
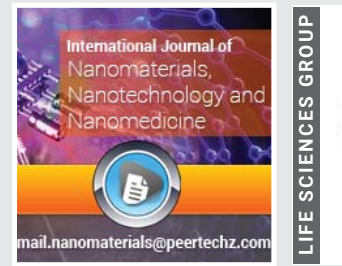

\section{Hemicellulose/poly(acrylic acid) semi-IPN magnetic nanocomposite hydrogel for lysozyme adsorption}

\author{
Tao Zhang and Xiao-Feng Sun*
}

Associate Professor, School of Chemistry and Chemical Engineering, Northwestern Polytechnical University, Xi'an, 710129, Shaanxi, P.R. China

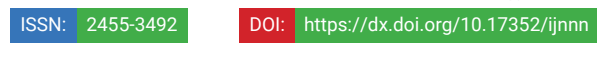

Received: 23 December, 2019

Accepted: 21 January, 2020

Published: 22 January, 2020

*Corresponding author: Xiao-Feng Sun, Associate Professor, School of Chemistry and Chemical Engineering, Northwestern Polytechnical University, P.R. China, Tel: 86-1336-3909336; Fax: 86-29-88431664; E-mail: xf001sn@nwpu.edu.cn; xf001sn@hotmail.com

Keywords: Hydrogel; Modified $\mathrm{Fe}_{3} \mathrm{O}_{4}$ nanoparticles; Lysozyme; Adsorption

ORCiD: http://orcid.org/0000-0002-7012-467X

https://www.peertechz.com

Check for updates

\begin{abstract}
A novel hemicellulose-based magnetic nanocomposite hydrogel was synthesized with modified Fe $\mathrm{O}_{4}$ nanoparticles using $\mathrm{H}_{2} \mathrm{O}_{2}-\mathrm{V}_{\mathrm{c}}$ as a green initiator system. The nanocomposite hydrogels were characterized by FT-IR, SEM and VSM, and the swelling properties of the hydrogels were also studied. The result demonstrated that the nanocomposite hydrogels had excellent $\mathrm{pH}$ sensitivity and magnetic property. This study found that the increases of the contents of Fe $\mathrm{O}_{4}$ nanoparticles resulted in higher cross-linking density, and the swelling ratio of the prepared hydrogels decreased. The VSM analysis showed that the magnetic hydrogels had superparamagnetic property, and the magnetization intensity increased with an increase in the content of $\mathrm{Fe}_{3} \mathrm{O}_{4}$ nanoparticles. The adsorption isotherm study of lysozyme demonstrated that both of Freundlich and Temkin isotherms models can describe the adsorption of lysozyme on the magnetic hydrogels. The smart swelling property and the high adsorption capacity of the magnetic hydrogel would expand it applications in drug delivery and magnetic separation aspects.
\end{abstract}

\section{Introduction}

Stimuli-responsive hydrogels can respond to external stimuli such as $\mathrm{pH}$, temperature, solvent, ionic strength, light, electric and magnetic field [1] and they have been investigated due to their potential applications in drug-delivery systems [2], biological separation, water treatment, soil conditioning [3-5] and so on. In recent years, magnetic hydrogels have attracted a great attention and applied in remote controlled drug release [6], cancer treatment, and toxic metal ion removal [7]. Some progresses in designing advanced magnetic materials and 3D multifunctional substrates/scaffolds had been made by using $\mathrm{Fe}_{3} \mathrm{O}_{4}$ nanoparticles and biomimetic iron-doped hydroxyapatite nanoparticles. A basic approach toward the development of nanocomposite magnetic scaffolds was suggested for advanced bone tissue engineering [8] and magnetic poly( $\varepsilon$-caprolactone)/ iron-doped hydroxyapatite nanocomposite substrate was prepared for advanced bone tissue engineering [9].

Hemicelluloses are the second most abundant native polymers in biomass, and hemicellulose-based hydrogels have been studied for applications in tissue engineering, adsorptions of proteins and drug delivery because of their biocompatibility and hydrophilicity [10-12]. There is currently promising research on preparing novel hemicellulose-based magnetic hydrogels for various biomedical applications.

In this paper, intelligent hydrogels based on hemicellulose and functional $\mathrm{Fe}_{3} \mathrm{O}_{4}$ nanoparticles were prepared using semiinterpenetrating network technique. The swelling properties of the magnetic hydrogels were studied in detail, and the adsorption of lysozyme onto the prepared hydrogels was also studied to test their potential for biomedical applications.

\section{Experimental}

\section{Materials}

Hemicelluloses (HC) were prepared according to a previous paper [11]. Ferric chloride hexahydrate $\left(\mathrm{FeCl}_{3} \cdot 6 \mathrm{H}_{2} \mathrm{O}\right)$ and sodium acetate $\left(\mathrm{CH}_{3} \mathrm{COONa}, \mathrm{NaAc}\right)$ were obtained from the Tianjian Chemical Reagent in China. Ethylene Glycol (EG) was purchased from Sinopharm company in China, and triethoxyvinylsilane $\left(\mathrm{CH}_{2}=\mathrm{CH}-\mathrm{Si}\left(\mathrm{OC}_{2} \mathrm{H}_{5}\right)_{3}, \mathrm{~A} 151\right)$ was purchased from the Shanghai Chemical Reagent Co. Ltd. in China. Acrylic 
acid (AAc) and $\mathrm{H}_{2} \mathrm{O}_{2}$ were purchased from Tianjin Kermel Chemical Reagent Company in China, and the cross-linker $\mathrm{N}$, $\mathrm{N}$-methylenebiacrylamide (Bis) was purchased from Tianjing Hongyan Chemical Reagent Factory in China. Lysozyme and Vitamin $\mathrm{C}(\mathrm{Vc})$ were obtained from J\&K scientific Ltd. All chemicals were of analytical grade and used without further purification. Deionized water was made using Ultra-pure water machine.

\section{Synthesis and surface modification of $\mathrm{Fe}_{3} \mathrm{O}_{4}$ nanopar- ticles}

$\mathrm{FeCl}_{3} \cdot 6 \mathrm{H}_{2} \mathrm{O}$ (1.3g) was dissolved in EG (40ml) followed by the addition of NaAc $(3.6 \mathrm{~g})$ and the mixture was magnetically stirred until being completely dissolved. The obtained homogeneous yellow solution was transferred into Teflonlined stainless-steel autoclave which was heated at $180^{\circ} \mathrm{C}$ for $10 \mathrm{~h}$. After reaction, the $\mathrm{Fe}_{3} \mathrm{O}_{4}$ particles were collected by applying an external magnetic field and washed with ethanol and water for several times. Finally, $\mathrm{Fe}_{3} \mathrm{O}_{4}$ particles were dried in a freezing dryer.

The modification of $\mathrm{Fe}_{3} \mathrm{O}_{4}$ nanoparticles were conducted by ultrasonically dispersing $\mathrm{Fe}_{3} \mathrm{O}_{4}$ particles in ethanol (20ml) and water (10ml) mixture solution for 30min, and then transferred into a three-necked flake. The silane coupling agent (A151, $0.33 \mathrm{ml}$ ) was added dropwise over a period, and the reaction mixture was stirred at $55^{\circ} \mathrm{C}$ for $7 \mathrm{~h}$. The products were collected by magnetic separation and washed with ethanol and water to remove the excess organic reagent. Finally, the nanoparticles were dried in a freezing dryer.

\section{Preparation of HC/PAAc semi-IPN magnetic hydrogel}

$0.2 \mathrm{~g}$ of $\mathrm{HC}$ was firstly dissolved in $9 \mathrm{ml}$ distilled water completely at room temperature, and then $0.06 \mathrm{~g}$ of modified $\mathrm{Fe}_{3} \mathrm{O}_{4}$ nanoparticles were dispersed in $1 \mathrm{ml}$ AAc, and the redox initiator system $\mathrm{H}_{2} \mathrm{O}_{2}-\mathrm{Vc}$ was added to the AAc mixture solution which was treated under ultrasound condition for $30 \mathrm{~s}$. Afterward, the hemicellulose solution was poured into the AAc mixture, and the solubilised cross-linker was added slowly, and this solution was stirred using mechanical agitation until hydrogel formed. The prepared hydrogels were taken out and cut into uniform size pieces and then soaked in distilled water for $48 \mathrm{~h}$. During this period, it was necessary to change the water regularly for washing away the unreacted monomer and initiator. Finally, the prepared hydrogels were pre-frozen at $-20^{\circ} \mathrm{C}$ and then freeze-dried at $-50^{\circ} \mathrm{C}$ for $48 \mathrm{~h}$. The synthesis conditions of the hydrogels are specified in Table 1.

Table 1: Synthesis conditions of the HC/PAAc semi-IPN magnetic hydrogels.

\begin{tabular}{|c|c|c|c|c|}
\hline Sample & $\mathrm{Fe}_{3} \mathrm{O}_{4} /(\mathbf{A A C}+\mathrm{HC}) /(\%)$ & $\mathrm{H}_{2} \mathbf{O}_{2}(\mathbf{m l})$ & $\mathbf{V c}(\mathbf{g})$ & $\mathrm{Bis}(\mathbf{g})$ \\
\hline Gel-1 & 0 & 0.02 & 0.02 & 0.02 \\
\hline Gel-2 & 5 & 0.02 & 0.02 & 0.02 \\
\hline Gel-3 & 15 & 0.02 & 0.02 & 0.02 \\
\hline Gel-4 & 20 & 0.02 & 0.02 & 0.02 \\
\hline Gel-5 & 15 & 0.02 & 0.02 & 0.015 \\
\hline Gel-6 & 15 & 0.02 & 0.02 & 0.025 \\
\hline
\end{tabular}

\section{Characterization}

The chemical structures of prepared hydrogels were analyzed using Fourier transform infrared spectroscopy (FTIR). Scanning electron microscopy (SEM) was used to observe the surface morphology of prepared hydrogels. Magnetic property of hydrogels was evaluated by using Vibration samples magnetometer (VSM).

\section{$\mathrm{pH}$ sensitivity test}

Swelling experiments were conducted in buffer solutions of measured $\mathrm{pH}$, and the ionic strength was adjusted to $0.1 \mathrm{M}$ using KCl. Hydrogels swollen to equilibrium were taken out and weighed after removing excess surface water with filter papers. Equilibrium swelling ratio $S(\mathrm{~g} / \mathrm{g})$ can be calculated by equation (1):

$$
S(g / g)=\left(W_{s}-W_{d}\right) / W_{d}
$$

where $W_{\mathrm{s}}(\mathrm{g})$ and $W_{d}(\mathrm{~g})$ are the weights of the swollen and dried hydrogels, respectively.

\section{Adsorption of lysozyme}

Gel-4 was placed into different concentrations of lysozyme solution for adsorption, and the container was then sealed with plastic wrap for $24 \mathrm{~h}$ at room temperature. Thereafter, the concentration of lysozyme solution was measured by UV spectrophotometer at $280 \mathrm{~nm}$. The adsorption amount is calculated by equation (2):

$$
Q=\left(C_{0}-C_{e}\right) V / m
$$

Where $Q(\mathrm{mg} / \mathrm{g})$ is the amount of lysozyme adsorbed on hydrogels; $V(\mathrm{~L})$ is the volume of the solution; $m(\mathrm{~g})$ is the mass quantity of Gel-4; $C_{o}(\mathrm{mg} / \mathrm{L})$ and $C_{e}(\mathrm{mg} / \mathrm{L})$ are the initial and equilibrium concentration of lysozyme solution, respectively.

\section{Results and discussion}

\section{Preparation of HC/PAAc semi-IPN magnetic hydrogel}

The proposed mechanism for the synthesis of HC/PAAc semi-IPN magnetic nanocomposite hydrogels is shown in Figure 1. Firstly, the redox initiator system $\mathrm{H}_{2} \mathrm{O}_{2}-\mathrm{Vc}$ generated oxygen anion radical $\left(\mathrm{O}_{2}^{-} \cdot\right)$ which initiated the polymerization of acrylic acid, and modified $\mathrm{Fe}_{3} \mathrm{O}_{4}$ nanoparticles joined into this polymerization by covalent bonds through the vinyl group on the surface. PAAc was cross-linked to form the threedimensional network after the addition of cross-linker Bis and HC was introduced into PAAc network by physical effect. Therefore, HC/PAAc semi-IPN magnetic hydrogels were obtained.

\section{FT-IR spectra of HC/PAAc semi-IPN magnetic hydrogels}

Figure 2 illustrates the FT-IR spectra of HC and HC/PAAc semi-IPN magnetic hydrogels. In the spectra of Gel-2 and Gel-4, the peaks at $1712 \mathrm{~cm}^{-1}$ and $1447 \mathrm{~cm}^{-1}$ were related to the $\mathrm{C}=\mathrm{O}$ stretching vibration and symmetrical stretching vibration of $-\mathrm{COOH}$, respectively $[11,12]$. The peak at $571 \mathrm{~cm}^{-1}$ was the characteristic absorption peak of $\mathrm{Fe}_{3} \mathrm{O}_{4}$ nanoparticles, which 


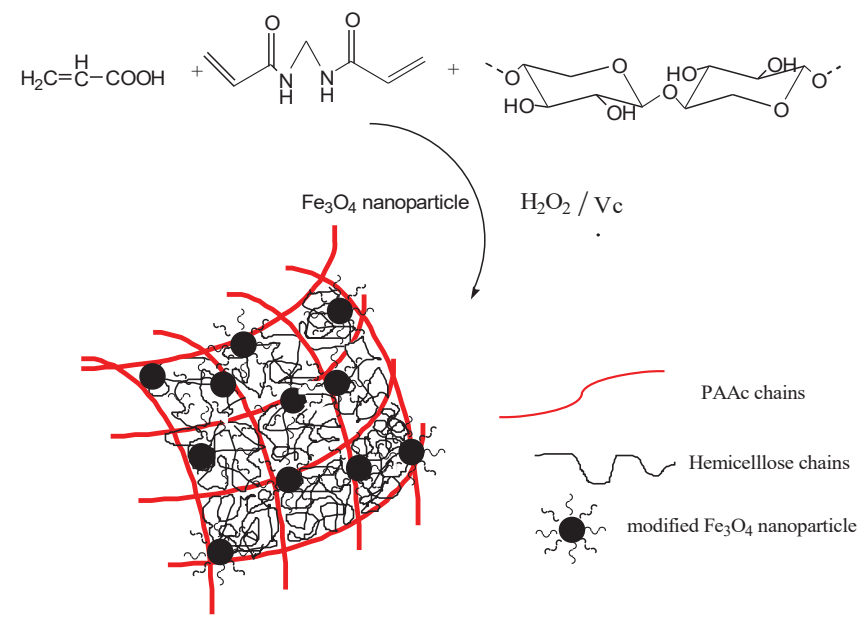

Figure 1: The proposed mechanism for the preparation of HC/PAAC semi-IPN magnetic hydrogels.

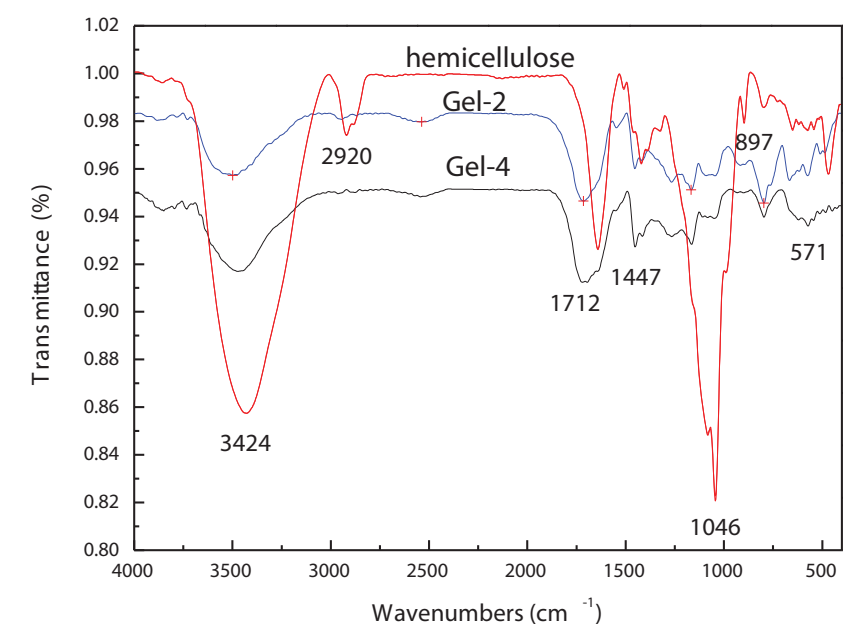

Figure 2: FT-IR spectra of $\mathrm{HC}$ and HC/PAAc semi-IPN magnetic nanocomposite hydrogels.

was assigned to the $\mathrm{Fe}^{2+}-\mathrm{O}^{2}$ stretching [13]. In $\mathrm{HC}$ spectrum, a strong band at $3424 \mathrm{~cm}^{-1}$ was caused by $\mathrm{O}-\mathrm{H}$ absorption and a symmetric $\mathrm{C}-\mathrm{H}$ absorption band appeared at $2920 \mathrm{~cm}^{-1}$. The obvious absorption peak at $1046 \mathrm{~cm}^{-1}$ was the characteristic of the $\mathrm{C}-\mathrm{O}$ and $\mathrm{C}-\mathrm{C}$ stretching and the glycosidic linkage $\mathrm{V}(\mathrm{C}-$ $\mathrm{O}-\mathrm{C}$ ) contributions. The sharp absorption peak at $897 \mathrm{~cm}^{-1}$ was assigned to frequency vibrations of $\mathrm{C}_{1}$ group and pyranose ring, which was the characteristic absorption peak of the glycosidic bond between sugar units [12]. These results indicated that $\mathrm{HC}$ was incorporated into the HC/PAAc semi-IPN magnetic hydrogels.

\section{Swelling behaviour of HC/PAAc semi-IPN magnetic hy- drogel}

Figure 3 shows the dependence of equilibrium swelling ratio of the hydrogels in buffer solutions. It was observed that the equilibrium swelling ratio rapidly increased at first and then changed slowly. Because the pKa value of $-\mathrm{COOH}$ of acrylic acid is 4.28 , the $-\mathrm{COOH}$ groups at lower $\mathrm{pH}(\mathrm{pH}<\mathrm{pKa})$ did not dissociate, and this enhanced the hydrogen bonding among hydrogel network chains [2]. However, the ionization of $-\mathrm{COOH}$ appeared at higher $\mathrm{pH}$, and the $\mathrm{COO}^{-}$groups led to strong electrostatic repulsion and an expanded network [11]. The decrease of the swelling ratio above $\mathrm{pH} 10$ would be due to a complete dissociation of acidic groups which led to an increase in the amount of mobile ions and a decrease in osmotic pressure.

Figures 3a,b show the effects of $\mathrm{Fe}_{3} \mathrm{O}_{4}$ nanoparticles and cross-linker on equilibrium swelling ratio, respectively. It is observed that the equilibrium swelling ratio decreased with an increase in the contents of $\mathrm{Fe}_{3} \mathrm{O}_{4}$ nanoparticles and cross linker. This was mainly because of the increased cross-linking density, and it resulted in a decrease of the distance between copolymer chains.

\section{Morphology of HC/PAAc semi-IPN magnetic hydrogel}

SEM images of Gel-2 and Gel-4 in Figure 4 indicated that the HC/PAAc semi-IPN magnetic nanocomposite hydrogel had a macro-porous structure, and the pore size of the hydrogels decreased when the amount of added $\mathrm{Fe}_{3} \mathrm{O}_{4}$ nanoparticles increased. The reason had been previously mentioned regarding to the effect of $\mathrm{Fe}_{3} \mathrm{O}_{4}$ nanoparticles on swelling ratio.

\section{Magnetic property of HC/PAAc semi-IPN magnetic hy- drogel}

Magnetic characterization of prepared nanocomposite nanocomposite hydrogels was performed under an external magnetic field of $15 \mathrm{kOe}$, as shown in Figure 5 . The specific saturation magnetizations of Gel-2, Gel-3 and Gel-4 are $2.94 \mathrm{emu} / \mathrm{g}, 8.72 \mathrm{emu} / \mathrm{g}$, and $12.18 \mathrm{emu} / \mathrm{g}$, respectively. As shown in Figure 5, the coercive force was close to zero, which is the typical characteristic of super-paramagnetic particle. The prepared hydrogels exhibited excellent magnetic response, which are important for the drug delivery and magnetic separation.

\section{Lysozyme Adsorption}

The effect of initial lysozyme concentration on adsorption performance of the prepared hydrogel was studied, and an increase of initial concentration led to a linear increase in the amount of adsorbed lysozyme, and the adsorption amount of lysozyme on the prepared hydrogel can be more than $180 \mathrm{mg} / \mathrm{g}$. Two theoretical isotherm models were used to analyze the adsorption of lysozyme on the prepared hydrogels. The Freundlich equation is the empirical relationship whereby it is assumed that the adsorption energy of a protein binding to a site on an adsorbent depends on whether or not the adjacent sites are already occupied. This isotherm model indicates a heterogeneous adsorption. The equation is expressed as following [14].

$$
\lg q_{e}=\lg K_{F}+(1 / n) \lg C_{e}
$$

where $K_{F}$ is the Freundlich constant, and $C_{e}$ is the equilibrium concentration of lysozyme solution, and $q_{e}$ is the equilibrium quantity of adsorbed lysozyme.

The Temkin isotherm model is shown as equation (4) [15] and it is assumed that the adsorption heat of all the molecules in the layer would decrease linearly with coverage due to sorbent interactions. 

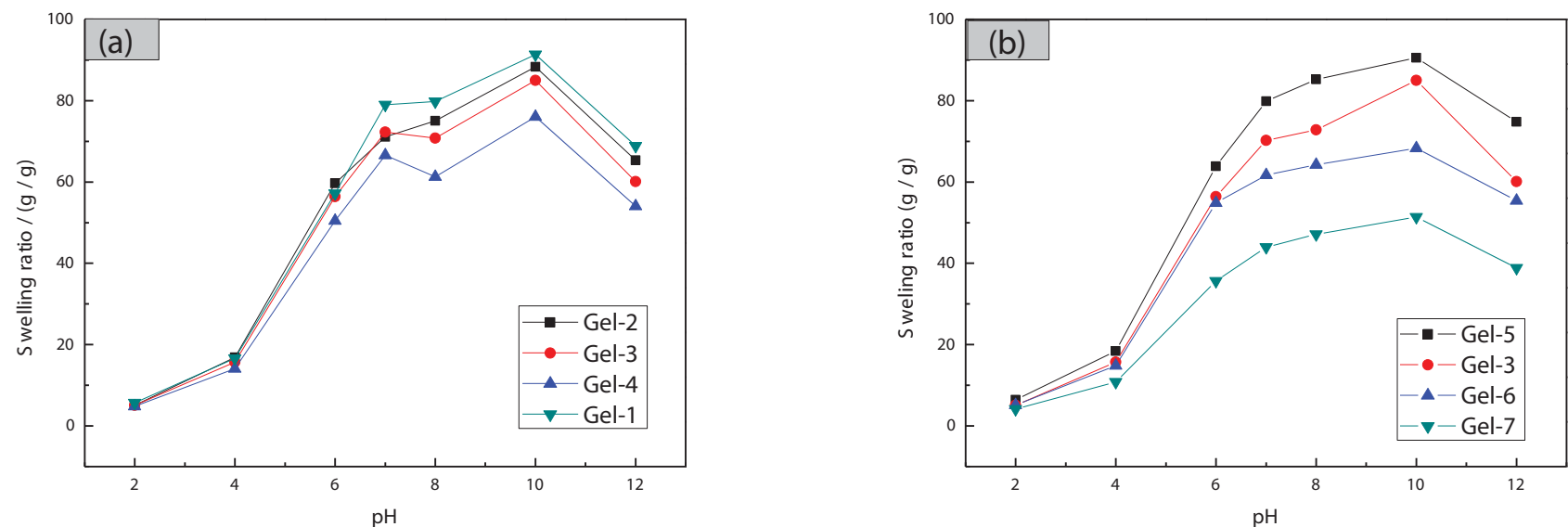

Figure 3: Equilibrium swelling ratio of $\mathrm{HC} / \mathrm{PAAc}$ semi-IPN magnetic nanocomposite hydrogels in different buffer solutions $\left(\mathrm{a}\right.$, hydrogels with various amount of $\mathrm{Fe}_{3} \mathrm{O}_{4}$ nanoparticles; $b$, hydrogels with various amount of Bis).

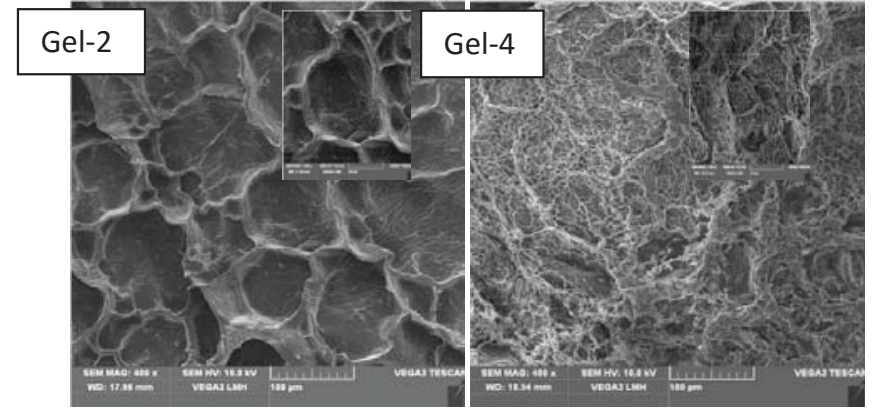

Figure 4: SEM photographs of the prepared nanocomposite hydrogels.

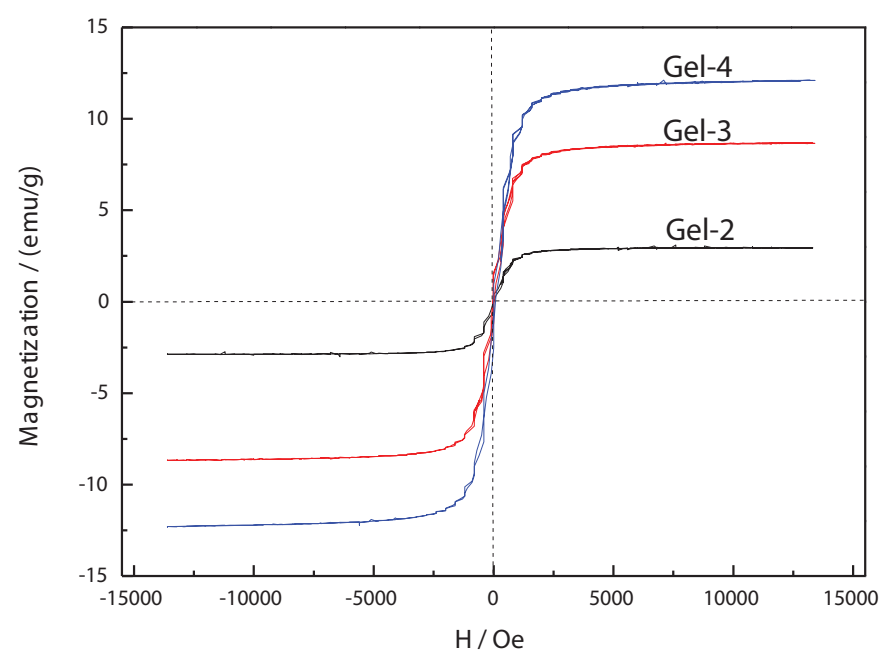

Figure 5: Magnetic hysteresis loop of the prepared nanocomposite hydrogels.

$\lg q_{e}=\lg K_{F}+(1 / n) \lg C_{e}$

Where $C_{e}$ is the equilibrium concentration of lysozyme solution; $A$ and $B$ represent isotherm constants.

Relevant adsorption parameters were also calculated according to the two adsorption isotherms equations, and the results are represented in Table 2. The correlation coefficient of Freundlich equation was much higher than 0.99, and $\mathrm{K}_{\mathrm{F}}$ and $\mathrm{n}$ were 1.6482 and 1 , respectively. This suggested that the adsorption of lysozyme on the prepared magnetic hydrogels is spontaneous. The Temkin data indicated that the adsorption heat would decrease linearly with the increase of adsorbent coverage, owing to the interaction between adsorbent and adsorbate. Both of Freundlich and Temkin simulations exhibited high $\mathrm{R}^{2}$, so the two models are considerably better fitted to the adsorption.

Table 2: Constants of the Freundlich and Temkin models for the lysozyme adsorption

\begin{tabular}{|c|c|c|c|c|c|}
\hline \multicolumn{3}{|c|}{ Freundlich } & \multicolumn{3}{c|}{ Temkin } \\
\hline$K_{F} /\left(\mathrm{mg}^{-1-n} \cdot \mathrm{g}^{-1} \cdot \mathrm{L}^{-n}\right)$ & $n$ & $R^{2}$ & $A$ & $B$ & $R^{2}$ \\
\hline 1.6482 & 1 & 0.9998 & 4.1006 & 0.0093 & 0.9735 \\
\hline
\end{tabular}

\section{Conclusion}

In summary, the HC/PAAc semi-IPN magnetic hydrogel was successfully fabricated using semi-interpenetrating network technique, and its application was studied for the adsorption of the lysozyme. The increases of the contents of $\mathrm{Fe}_{3} \mathrm{O}_{4}$ nanoparticles and Bis resulted in higher cross-linking density; thus the swelling ratio of the prepared hydrogels decreased. The VSM analysis showed that the HC/PAAc semiIPN magnetic hydrogels had superparamagnetic property, and the magnetization intensity increased with an increase in the content of $\mathrm{Fe}_{3} \mathrm{O}_{4}$ nanoparticles. The adsorption isotherm study of lysozyme demonstrated that both of Freundlich and Temkin isotherms models are suitable for describing the adsorption of lysozyme on the HC/PAAc semi-IPN magnetic hydrogels. The smart swelling property and the high adsorption capacity of the HC/PAAc semi-IPN magnetic hydrogel would expand it applications in drug delivery and magnetic separation aspects.

\section{Acknowledgements}

The authors appreciate the supports by "the Fundamental Research Funds for the Central Universities" (310201911cx012) 
and "the Seed Foundation of Innovation and Creation for Graduate Students in Northwestern Polytechnical University" (Z2020230).

\section{References}

1. Suzuki D, Yamakawa S (2012) Hydrogel particles as a particulate stabilizer for dispersion polymerization. Langmuir 28: 10629-10634. Link: http://bit.ly/3anCciW

2. Huang $\mathrm{Y}, \mathrm{Yu} \mathrm{H}$, Xiao C (2007) pH-sensitive cationic guar gum/poly (acrylic acid) polyelectrolyte hydrogels: swelling and in vitro drug release. Carbohyd Polym 69: 774-783. Link: http://bit.ly/38q4MhR

3. Ozay O, Ekici S, Baran Y, Kubilay S, Aktas N, et al. (2010) Utilization of magnetic hydrogels in the separation of toxic metal ions from aqueous environments. Desalination 260: 57-64. Link: http://bit.ly/2GajL3s

4. Alveroğlu E, Sözeri H, Baykal A, Kurtan U, Şenel M (2013) Fluorescence and magnetic properties of hydrogels containing $\mathrm{Fe}_{3} \mathrm{O}_{4}$ nanoparticles. J Mol Struct 1037: 361-366. Link: http://bit.ly/2NMbVRH

5. Paulino AT, Pereira AGB, Fajardo AR, Erickson $K$, Kipper $M J$, et al. (2012) Natural polymer-based magnetic hydrogels: potential vectors for remote-controlled drug release. Carbohyd Polym 90: 1216-1225. Link: http://bit.ly/2THJgBd

6. Wu CJ, Gaharwar AK, Chan BK, Schmidt G (2011) Mechanically tough pluronic F127/laponite nanocomposite hydrogels from ovalently and physically crosslinked networks. Macromolecules 44: 8215-8224. Link: http://bit.ly/38sbfck

7. Ozay O, Ekici S, Baran Y, Aktas N, Sahiner N (2009) Removal of toxic metal ions with magnetic hydrogels. Water Res 43: 4403-4411. Link: http://bit.ly/2vaheEb
8. De Santis R, Gloria A, Russo T, D'Amora U, Zeppetelli S, et al. (2011) A basic approach toward the development of nanocomposite magnetic scaffolds for advanced bone tissue engineering. J Appl Polym Sci 122: 3599-3605. Link: http://bit.ly/38pavEx

9. Gloria A, Russo T, D’Amora U, Zeppetelli S, D'Alessandro T, et al. (2013) Magnetic poly( $\varepsilon$-caprolactone)/iron-doped hydroxyapatite nanocomposite substrates for advanced bone tissue engineering. J R Soc Interface 10: 1-11. Link: http://bit.ly/2ttdD3J

10. Söderqvist Lindblad M, Albertsson AC, Ranucci E, Laus M, Giani E (2005) Biodegradable polymers from renewable sources: rheological characterization of hemicellulose-based hydrogels. Biomacromolecules 6: 684-690. Link: http://bit.ly/3av3V1i

11. Sun XF, Wang HH, Jing ZX, Mohanathas R (2013) Hemicellulose-based pHsensitive and biodegradable hydrogel for controlled drug delivery. Carbohyd Polym 92: 1357-1366. Link: http://bit.ly/37hLY48

12. Sun XF, Sun RC, Fowler P, Baird MS (2005) Extraction and characterization of original lignin and hemicelluloses from wheat straw. J Agr Food Chem 53 860-870. Link: http://bit.ly/2Rb1BVv

13. Su J, Cao M, Ren L, Hu C (2011) $\mathrm{Fe}_{3} \mathrm{O}_{4}$-graphene nanocomposites with improved lithium storage and magnetism properties. J Phys Chem C 115 14469-14477. Link: http://bit.ly/2tAQOLe

14. Bayramoğlu G, Yılmaz M, Arıca MY (2003) Affinity dye-ligand poly(hydroxyethy methacrylate)/chitosan composite membrane for adsorption lysozyme and kinetic properties. Biochem Eng J 13: 35-42. Link: http://bit.ly/2NL7eYh

15. Vijayaraghavan K, Padmesh TVN, Palanivelu K, Velan M (2006) Biosorption of nickel(II) ions onto sargassum wightii: application of two-parameter and three-parameter isotherm models. J Hazard Mater 133: 304-308. Link: http://bit.ly/2tC5hGU
Discover a bigger Impact and Visibility of your article publication with Peertechz Publications

Copyright: ( $) 2020$ Zhang T, et al. This is an open-access article distributed under the terms of the Creative Commons Attribution License, which permits unrestricted use distribution, and reproduction in any medium, provided the original author and source are credited. 